\title{
A small molecule inhibitor MCC950 ameliorates kidney injury in diabetic nephropathy by inhibiting NLRP3 inflammasome activation
}

This article was published in the following Dove Press journal: Diabetes, Metabolic Syndrome and Obesity: Targets and Therapy

\author{
CongXiao Zhang ${ }^{1,2, *}$ \\ XinWang Zhu',* \\ LuLu Li ${ }^{1}$ \\ TianKui Ma' \\ Mai Shi' \\ Ying Yang \\ QiuLing Fan'
}

'Department of Nephrology, The First Hospital of China Medical University, Shenyang I I000I, People's Republic of China; ${ }^{2}$ Blood Purification Center, Shenyang the 4th Hospital of People, Shenyang II003I, People's Republic of China

*These authors contributed equally to this work
Correspondence: QiuLing Fan

Department of Nephrology, the First Hospital of China Medical University, Heping District of Nanjing North Street No. I55, Shenyang I I000I, People's Republic of China

Tel +86248328 236I

Fax +862483282377

Email cmufq|@I63.com
Background: Diabetic nephropathy (DN) is a lethal diabetic microvascular complication characterized by chronic low-grade inflammation. The NOD-like receptor pyrin domaincontaining protein 3 (NLRP3) inflammasome is implicated in the progression of DN. MCC950 is a selective and potent inhibitor of NLRP3; however, its efficacy in DN requires further investigation.

Methods: To investigate the efficacy of MCC950 in DN, eight-week-old type 2 diabetic $\mathrm{db} / \mathrm{db}$ mice received injections of MCC950 intraperitoneally $(10 \mathrm{mg} / \mathrm{kg})$ twice per week for 12 weeks. Urinary albumin-to-creatinine ratio (ACR) and neutrophil gelatinase-associated lipocalin (NGAL), renal function, pathological changes, markers of podocyte and fibrosis and NLPR3/caspase-1/IL-1 $\beta$ expression in the renal cortices of $d b / d b$ mice were evaluated. High-glucose (HG)-treated rat glomerular mesangial cells were treated with various concentrations of MCC950 for 48 hrs. Markers of fibrosis and NLPR3/caspase-1/IL-1 $\beta$ expression in the glomerular mesangial cells were measured.

Results: The NLRP3 inflammasome was activated in $d b / d b$ mice and HG-induced mesangial cells by upregulating NLRP3/caspase-1/IL-1 $\beta$ pathway. Inhibition of the NLRP3 inflammasome with MCC950 reduced the production of active caspase- 1 and active IL-1 $\beta$ in $d b / d b$ mice and HG-induced mesangial cells. MCC950 reduced serum creatinine, urinary ACR and NGAL, attenuated mesangial expansion with increased matrix and tubular dilatation, alleviated thickened glomerular basement membrane (GBM) and foot process fusion without affecting body weight and blood glucose levels in $d b / d b$ mice. MCC950 increased the expression of podocin in $d b / d b$ mice, and decreased the expression of TGF- $\beta 1$, fibronectin, collagen I and $\alpha$-smooth muscle actin ( $\alpha$-SMA) in renal cortices of $d b / d b$ mice and HGinduced mesangial cells.

Conclusion: MCC950 ameliorated renal function, thickened GBM, podocyte injury and renal fibrosis in $d b / d b$ mice, and decreased the production of fibrosis markers in HG-induced mesangial cells. MCC950 effectively ameliorated diabetic kidney injury by inhibiting NLRP3/caspase-1/IL-1 $\beta$ pathway, which may be a potential therapeutic strategy to prevent the progression of DN.

Keywords: diabetic nephropathy, MCC950, NLRP3 inflammasome, $d b / d b$ mice, mesangial cells

\section{Introduction}

Diabetic nephropathy (DN), a common diabetic microvascular complication, is the primary cause of end-stage renal disease (ESRD) worldwide. ${ }^{1,2}$ Type 2 diabetes mellitus (T2DM) patients occupy almost $50 \%$ of new cases of ESRD in the US 
population. ${ }^{1,3}$ Patients with ESRD as a result of diabetes require renal replacement therapy, contributing to considerable individual and socioeconomic costs worldwide. ${ }^{4}$

Recent studies have reported persistent inflammation in circulatory and renal tissues; in particular, NLRP3 inflammasome-mediated inflammation is crucial to the pathogenesis of DN. ${ }^{2,5}$ NLRP3 inflammasome activation is upregulated in type 2 diabetic patients. ${ }^{6}$ NLRP3 is a useful biomarker discriminating DN patients from type 2 diabetic patients. ${ }^{7}$ In the innate immune system, nucleotide-binding oligomerization domain (NOD)-like receptors (NLRs) are pattern recognition receptors that recognize pathogen-associated molecular patterns and dangerassociated molecular patterns (DAMPs). ${ }^{8}$ Upon detection of cellular stress, intracellular NOD-like receptor pyrin domain-containing protein 3 (NLRP3) combines with apoptosis-associated speck-like protein (ASC) that contains a caspase recruitment domain (CARD) and binds pro-caspase-1 to form the NLRP3 inflammasome. ${ }^{9,10}$ The NLRP3 inflammasome promotes pro-caspase-1 selfcleavage to generate the active caspase- $1 \mathrm{p} 10 / \mathrm{p} 20$ tetramer that induces pro-IL-1 $\beta$ maturation and activates IL- $1 \beta$ p 17 secretion. ${ }^{2,5}$ NLRP3 inflammasome activation occurs both in innate immune cells and in nonimmune cells intrinsic renal cells (mesangial cells, podocytes and epithelial cells) ${ }^{11,12}$ therefore, targeting the NLRP3 inflammasome may be a promising therapeutic strategy for $\mathrm{DN}{ }^{2}$

MCC950 is a highly selective, potent small molecule inhibitor of NLRP3; it has been associated with the treatment of several diseases. ${ }^{13,14}$ Early NLRP3 inhibition by MCC950 prevented kidney fibrosis in a murine model of crystal nephropathy. ${ }^{15}$ MCC950 reduced renal inflammation, fibrosis and dysfunction in mice with established hypertension. ${ }^{16}$ NLRP3 inflammasome inhibition by MCC950 reduced atherosclerotic lesion development. ${ }^{17}$ MCC950 attenuated severe, steroid-resistant asthma. ${ }^{18}$ The cytotoxicity of MCC950 was tested using human kidney and liver cell lines HEK293 or HepG2, and no evidence of toxicity was found. ${ }^{14}$ Nevertheless, the efficacy of MCC950 for DN requires further study. The $d b / d b$ mouse was identified initially in 1966 at Jackson Labs ${ }^{19}$ and is widely used as a mouse model of type 2 diabetic nephropathy, because $d b / d b$ mice and patients with DN share similar renal pathological changes. ${ }^{20}$ To demonstrate whether MCC950 protects against progression of DN, we used type 2 diabetic $d b / d b$ mice in vivo and glomerular mesangial cells in vitro to investigate NLPR3/caspase-1/ IL-1 $\beta$ expression and the efficacy of MCC950.

\section{Materials and methods}

\section{Animals}

Seven-week-old diabetic male $d b / d b$ (C57BLKS/J-lepr ${ }^{\mathrm{db}} /$ lepr ${ }^{\mathrm{db}}$ ) mice and non-diabetic male $d b / m$ littermates $\left(\mathrm{C} 57 \mathrm{BLKS} / \mathrm{J}-\right.$ lepr $^{\mathrm{db} /+}$ ) were purchased from the Model Animal Research Center of Nanjing University (Nanjing, China). The mice were maintained in a room with controlled environment $\left(23 \pm 3^{\circ} \mathrm{C}, 50 \% \pm 20 \%\right.$ humidity, 12 -hr light/dark cycle) with free access to water and food. All procedures were carried out according to the approved Institutional Animal Care and Use Committee protocol of China Medical University (Number: 16095M). The mice were randomly divided into three groups ( $\mathrm{n}=10$ per group). For the MCC950 treated group ( $d b / d b+$ MCC 950), $d b / d b$ mice were treated with $10 \mathrm{mg} / \mathrm{kg}$ of MCC950 (Selleck Chemicals, Houston, USA) twice per week intraperitoneally from 8 weeks of age to 20 weeks of age. The control $(d b / m)$ and untreated groups $(d b / d b)$ received an equal volume of vehicle (saline). The treatment lasted 12 weeks. Body weight (BW) was measured weekly, and fasting blood glucose levels were measured every 4 weeks. All mice were sacrificed at 20 weeks of age. All mice were anesthetized with pentobarbital, and blood samples were collected by orbital vein bleeding. Kidney weight (KW) was measured after cardiac perfusion as described previously. ${ }^{21}$ Renal cortical samples were harvested for subsequent studies.

\section{Cell culture}

The rat mesangial cell line HBZY-1 was purchased from the China Center for Type Culture Collection (Wuhan, China) and were cultured in low-glucose $(5.5 \mathrm{mmol} / \mathrm{L})$ DMEM (Hyclone, SH30021, USA) with 10\% FBS (Bioind, 04-001-1A, USA), $100 \mu \mathrm{g} / \mathrm{mL}$ streptomycin and $100 \mathrm{U} / \mathrm{mL}$ penicillin (Gibco, 15140-122, USA). The cells were routinely cultured at $5 \% \mathrm{CO}_{2}$ and $37^{\circ} \mathrm{C}$ with saturated humidity, digested and passaged after $85 \%$ cell confluence. At $24 \mathrm{hrs}$ after cell passaging and attachment, the cells were divided into five groups and cultured for 48 hrs: 1) the normal-glucose group (NG) that received $5.5 \mathrm{mmol} / \mathrm{L}$ glucose (Sigma, A24940-01,USA); 2) the high-glucose group (HG) that received $30 \mathrm{mmol} / \mathrm{L}$ glucose with vehicle (DMSO); 3) the $0.01 \mu \mathrm{M}$ MCC950 group (0.01) that received $30 \mathrm{mmol} / \mathrm{L}$ glucose with 0.01 $\mu \mathrm{mol} / \mathrm{L}$ MCC950; 4) the $0.1 \mu \mathrm{M}$ MCC950 group (0.1) that received $30 \mathrm{mmol} / \mathrm{L}$ glucose with $0.1 \mu \mathrm{mol} / \mathrm{L}$ MCC950 and 5) the $1 \mu \mathrm{M} \mathrm{MCC950} \mathrm{group} \mathrm{(1)} \mathrm{that}$ 
received $30 \mathrm{mmol} / \mathrm{L}$ glucose with $1 \mu \mathrm{mol} / \mathrm{L}$ MCC950. We tested cell viability at 0 and 48 hrs by light microscopy and trypan blue exclusion.

\section{Blood examination}

Serum samples were used to measure serum creatinine and blood urea nitrogen (BUN) on a VITROS 950 automatic biochemical analyzer (Johnson \& Johnson, New Brunswick, NJ).

\section{ELISA assay}

Mice were housed in individual metabolic cages, and 24-hr urine samples were collected every 4 weeks. Urinary albumin and neutrophil gelatinase-associated lipocalin (NGAL) were determined with a mouse ELISA kit (Cloud-Clone Corp, CEB028Mu, SEB388Mu, China) in accordance with the manufacturer's instructions. Urinary creatinine concentrations were determined with a creatinine assay kit (NJJCBIO, C011-2, China). Urinary albumin excretion was expressed as urinary albumin concentration versus creatinine concentration ratio (ACR, $\mu \mathrm{g} / \mathrm{mg}$ ). ELISA kits were also used for the measurement of levels of IL-1 $\beta$ in renal cortical tissue homogenates and cell culture supernatants (CUSABIO, E08054m, E08055r, China) in accordance with the manufacturer's instructions.

\section{Histologic analysis}

Renal cortices were fixed in an alcohol-formalin-acetic acid solution (AFA) and were embedded in paraffin. The sections $(3 \mu \mathrm{m})$ were stained with HE, periodic acid-Schiff (PAS) and Masson trichrome. The semi-quantitative index was used to evaluate the degree of glomerular sclerosis by PAS staining and tubulointerstitial damage by Masson staining, based on an average of 20 glomeruli per mouse. Glomerular sclerosis was scored from 0 to 5 as follows: 0 , normal; 1 , the mesangial matrix and slight glomerular damage and/or hyalinosis involving $<10 \%$ of the glomerulus; $2,10-20 \% ; 3,20-30 \% ; 4,30-40 \%$; and $5,>40 \%$. Tubular damage was scored by the percentage of injured tubules (tubular dilation, interstitial inflammation and fibrosis) from 0 to 5 as follows: 0 , normal; 1 , tubular lesion $<10 \% ; 2,10-20 \% ; 3,20-30 \% ; 4,30-40 \%$; and $5,>40 \%$. ${ }^{22}$ Two pathologists performed a blinded analysis of all sections.

\section{Transmission electron microscopy (TEM)}

Renal cortices $\left(1 \mathrm{~mm}^{3}\right)$ were fixed with $2.5 \%$ glutaraldehyde at $4^{\circ} \mathrm{C}$ and were examined using a transmission electron microscope (H-7650, Olympus, Japan). Electron micrographs were used to determine the glomerular basement membrane (GBM) thickness and podocyte foot process width as previously described. ${ }^{23}$

\section{Immunohistochemistry (IHC)}

The deparaffinized and rehydrated sections $(3 \mu \mathrm{m})$ of paraffin-embedded renal cortices were subjected to heatmediated antigen retrieval and incubated with $3 \% \mathrm{H}_{2} \mathrm{O}_{2}$ for 10 mins. Sections were then incubated overnight at $4^{\circ}$ $\mathrm{C}$ with primary antibodies against proliferating cell nuclear antigen (PCNA) (Wanleibio, w102208, 1:200), phosphor-

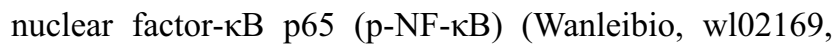
1:100), podocin (Abcam, ab181143, 1:500), fibronectin (Proteintech, 15613-1-AP, 1:200), $\alpha$-SMA (Abcam, ab5694, 1:50), NLRP3 (Cell Signaling Technology, 15101, 1:200), caspase-1 (Abcam, ab1872, 1:25) or IL-1 $\beta$ (Cell Signaling Technology, 12242, 1:100). For PCNA, $\mathrm{p}-\mathrm{NF}-\mathrm{\kappa B}$ and podocin, the percentage of a positively stained area over the whole glomerular area was calculated. For other antibodies, the micrographs were quantified blindly using Image-Pro Plus 6.0 software and were expressed as the ratio of integrated optical density to the whole area. Each renal section was counted for at least 10 images.

\section{Western blot (WB) analysis}

Total proteins from renal cortices were extracted with icecold RIPA lysis buffer (Beyotime, China), and protein concentrations were measured by BCA Protein Assay Kit (Beyotime, China). Equal amount of proteins was separated by SDS-PAGE and transferred to PVDF membranes (Millipore, USA). Membranes were blocked in 5\% nonfat milk at room temperature for $1 \mathrm{hr}$ and then incubated overnight at $4{ }^{\circ} \mathrm{C}$ with primary antibodies to podocin (Abcam, ab181143, 1:2000), TGF- $\beta 1$ (Proteintech, 18978, 1:1000), collagen I (Proteintech, 14695, 1:1000), $\alpha$-SMA (Abcam, ab5694, 1:1000), NLRP3 (CST, 15101, 1:500), caspase-1 (Abcam, ab1872, 1:400), IL-1 $($ CST, 12242, 1:500) and $\beta$ actin (ZSGB-BIO, TA-09,1:3000). After incubation with the appropriate secondary antibodies (Abbkine, 1: 10,000) at room temperature for $1 \mathrm{hr}$, target bands were detected by enhanced chemiluminescence substrate (Abbkine, USA). Each Western blot was performed at least three times. Semiquantitative analysis was measured using ImageJ software.

\section{RNA extraction and real-time qPCR}

Total RNA from renal cortices was extracted using TRIzol (Invitrogen, USA). Reverse transcription was performed 
using a Prime Script reverse transcription reagent kit (9108, TaKaRa Bio, Japan), and RNA ( $1 \mu \mathrm{g})$ was reverse transcribed into cDNA. Real-time qPCR was performed using TB Green reagent on an ABI 7500 real-time PCR System (RR820A, TaKaRa Bio, Japan) in accordance with the manufacturer's instructions. In vivo experiments, the primer sequences of mice used for mRNA detection were as follows: TGF- $\beta 1$, forward 5'-CAACAATTCCTGGCGTTAC CTTGG-3' and reverse 5'-GAAAGCCCTGTATTCCGTCT CCTT-3'; fibronectin, forward 5'-ATGAGGAGGTCC AAATCG-3' and reverse 5'-GAACGGCGTCCAAGA G-3'; Collagen I, forward 5'-TGCCGTGACCTCAAG ATGTG-3' and reverse 5'-CACAAGCGTGCTGTAG GTGA-3'; $\beta$-actin, forward 5'-GAGACCTTCAACACCC CAGC-3' and reverse 5'-ATGTCACGCACGATTTCCC-3'. In vitro experiment, the primer sequences of cells were generated for mRNA detection: TGF- $\beta 1$, forward $5^{\prime}$ ATGGTGGACCGCAACAAC-3' and reverse 5'-GAGC ACTGAAGCGAAAGC-3'; fibronectin, forward 5'-AC GGTGGCAACTCAAAC-3' and reverse 5'-GGGAAG TGGCACAAGG-3'; Collagen I, forward 5'-AAACGGG AGGGCGAGTG-3' and reverse 5'-CATAGGACATC TGGGAAGCAA-3'; $\beta$-actin, forward $5^{\prime}$ - GGAGATTA CTGCCCTGGCTCCTAGC-3' and reverse 5'-GGCCG GACTCATCGTACTCCTGCTT-3'. PCR was carried out at $95^{\circ} \mathrm{C}$ for $30 \mathrm{~s}$, followed by 40 cycles each of $95^{\circ} \mathrm{C}$ for $5 \mathrm{~s}, 60^{\circ} \mathrm{C}$ for $34 \mathrm{~s}$. The relative quantitative expression was calculated by $2^{-\Delta \Delta C t}$ method. ${ }^{21}$ Each group was examined in triplicate.

\section{Immunofluorescence}

The cells were fixed in 4\% paraformaldehyde for 15 mins at room temperature after washing with $\mathrm{PBS}$, permeabilized for 30 mins with $0.5 \%$ Triton X-100 in PBS and blocked for $1 \mathrm{~h}$ at $37^{\circ} \mathrm{C}$ with $5 \%$ BSA. The cells were incubated with caspase-1 (Abcam, ab1872, 1:25) overnight at $4^{\circ} \mathrm{C}$ in a humidified chamber. After washing with PBS, cells were incubated with secondary antibody (Abbkine, A23420, 1:500) for $1 \mathrm{hr}$ at $37^{\circ} \mathrm{C}$ in a darkened humidified chamber. Cell nuclei were stained with DAPI. Fluorescence was observed using a confocal laser scanning microscope (Nikon A1R, Japan).

\section{Statistical analysis}

Quantitative data were presented as mean \pm standard error of mean from three independent experiments. Statistical analysis was performed using GraphPad Prism 7.0 software. Differences between several groups were evaluated with ANOVA. Differences between two groups were assessed using the Student's $t$-test. A value of $P<0.05$ was regarded as statistically significant.

\section{Results}

\section{MCC950 decreased the urinary} albumin-to-creatinine ratio and improved renal function and pathological changes in $\mathrm{db} / \mathrm{db}$ mice

BW and blood glucose were higher in $d b / d b$ mice than in nondiabetic $\mathrm{db} / \mathrm{m}$ mice; however, BW and blood glucose in $\mathrm{db} / \mathrm{db}$ mice were not affected by MCC 950 treatment $(P>0.05$, Figure $1 \mathrm{~A}$ and $\mathrm{B})$. The ratio of kidney weight to body weight (KW/ $\mathrm{BW})$ in $d b / d b$ mice was lower than that of $d b / \mathrm{m}$ mice; however, the KW/BW ratio showed no statistical difference between the $d b / d b$ and $d b / d b+\mathrm{MCC} 950$ groups ( $P>0.05$, Figure 1C). Serum creatinine of $d b / d b$ mice was higher than that of $d b / m$ mice, and MCC950 significantly blunted the diabetes-induced increase in serum creatinine $(P<0.05$, Figure 1D). There was no significant difference in BUN between the $d b / m, d b / d b$ and $d b / d b+$ MCC950 groups ( $P>0.05$, Figure 1E). Compared to $d b /$ $m$ mice, urinary albumin to creatinine ratio (ACR) of $d b / d b$ mice was greater and was effectively reduced by MCC950 treatment $(P<0.05$, Figure $1 \mathrm{~F})$. The degree of decreasing urinary ACR increased with the prolongation of treatment time $(\mathrm{F}=13.95 ; P<0.01)$. Urinary $\mathrm{NGAL}$ as a marker of tubular injury was also reduced by MCC 950 treatment in $d b / d b$ mice $(P<0.05$, Figure $1 \mathrm{G})$. HE, PAS and Masson's staining showed mesangial matrix expansion, glomerular hypertrophy, tubular dilation and interstitial inflammation in $d b / d b$ mice (Figure $1 \mathrm{H})$. The glomerular sclerosis index and tubulointerstitial damage index were higher in $d b / d b$ mice than in $d b / m$ mice $(P<0.05$, Figure 1I and $\mathrm{J})$. However, both were significantly attenuated by MCC 950 treatment, with MCC950 ameliorating the glomerular sclerosis and tubular damage of DN. Expression levels of PCNA and $\mathrm{p}-\mathrm{NF}-\kappa \mathrm{B}$ were greater in the nucleus of glomeruli in $\mathrm{db} / \mathrm{db}$ mice than in $\mathrm{db} / \mathrm{m}$ mice, which confirmed that mesangial cells were proliferated and activated, and were inhibited by MCC950 treatment as measured by IHC $(P<0.05$, Figure $1 \mathrm{~K}-\mathrm{N})$.

\section{MCC950 attenuated podocyte injury in $\mathrm{db} / \mathrm{db}$ mice}

Electron microscope images showed that the increased GBM thickness and foot process width were significantly attenuated by MCC950 treatment $(P<0.05$, Figure $2 \mathrm{~A}-\mathrm{C})$. Lower expression of podocin as a marker of podocyte in renal cortical tissue 

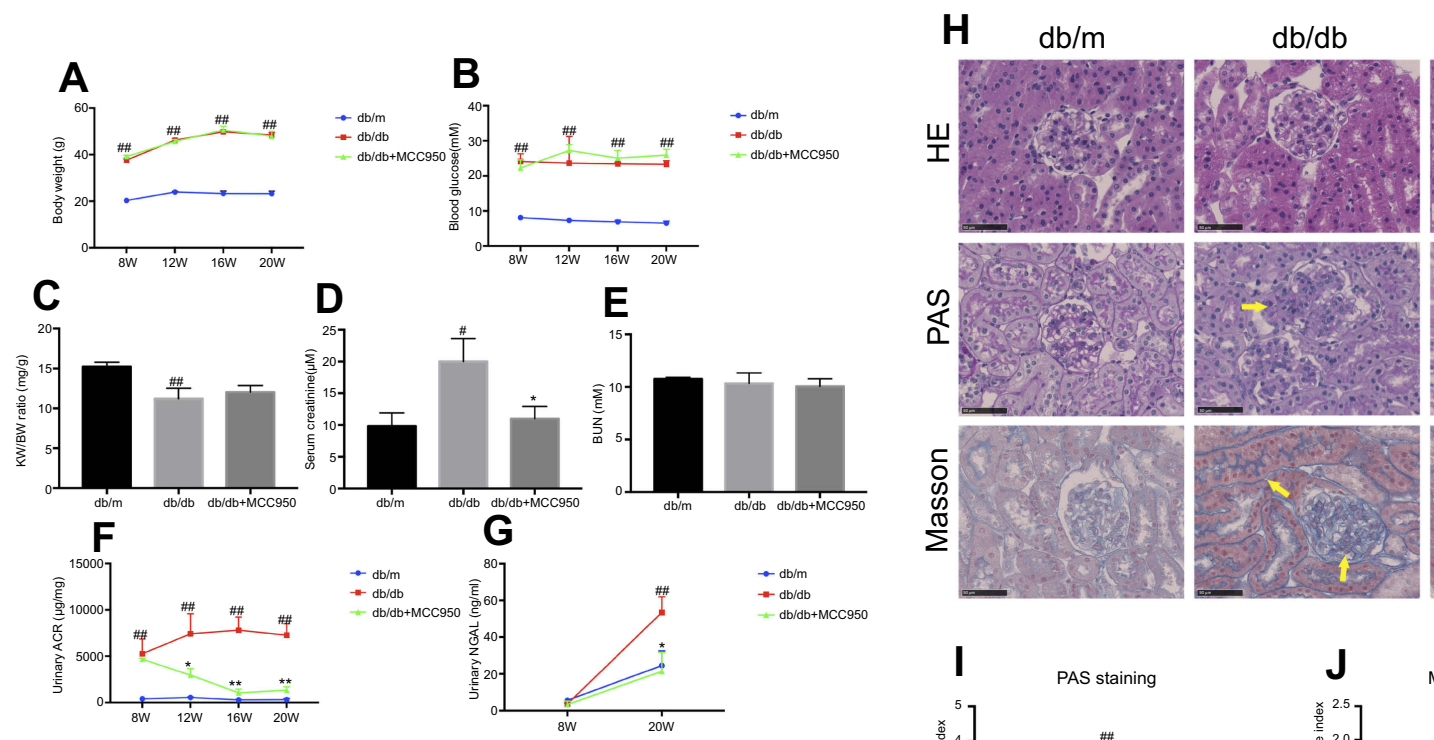

$\mathrm{db} / \mathrm{db}+\mathrm{MCC} 950$
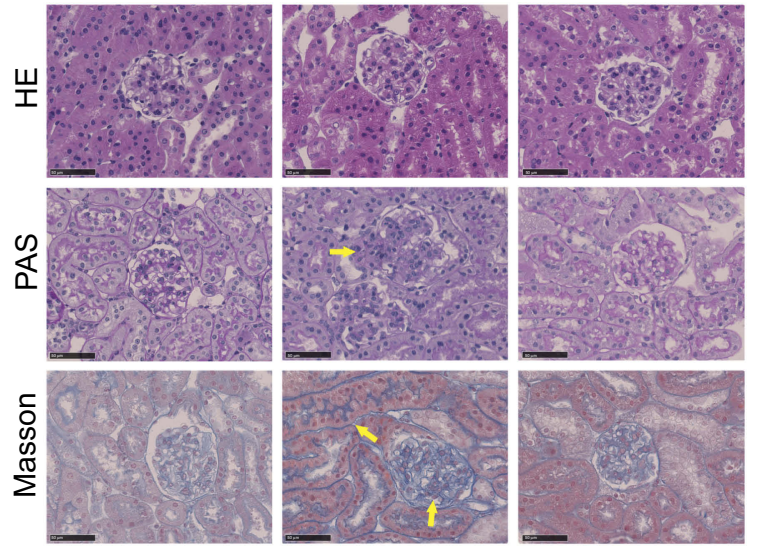

E
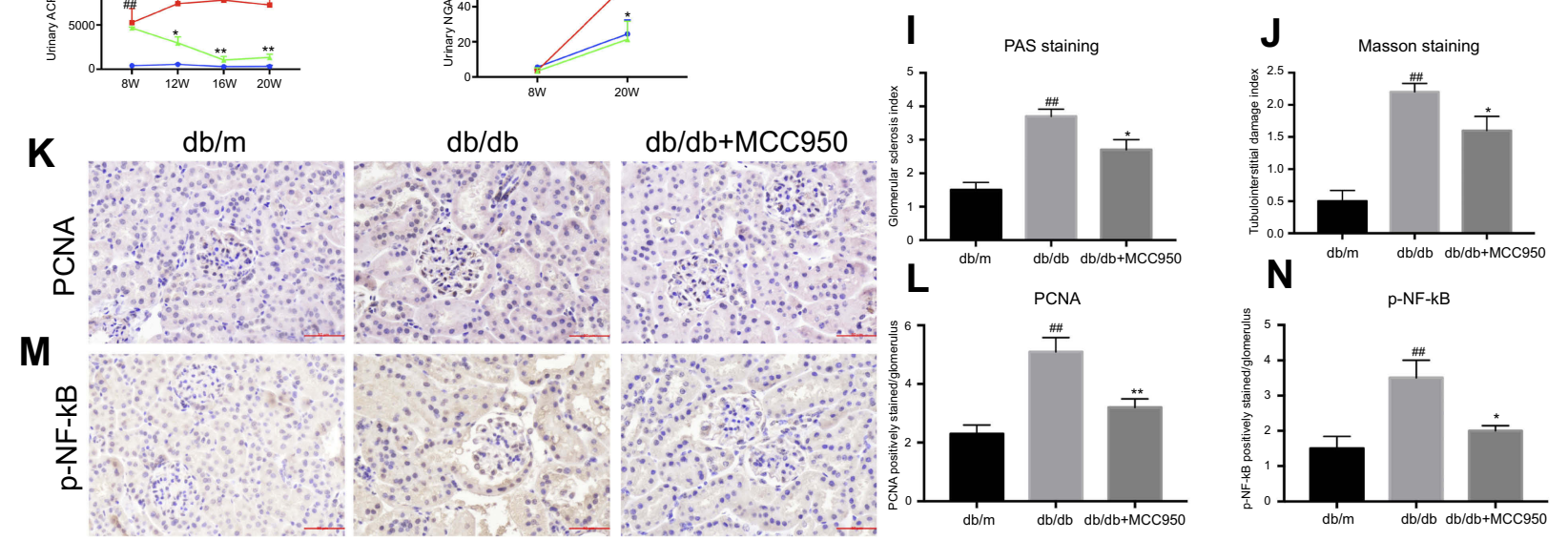

Figure I MCC950 decreased the urinary albumin-to-creatinine ratio and improved renal function and pathological changes in $\mathrm{db} / \mathrm{db}$ mice.

Notes: (A) Body weight and (B) blood glucose from $d b / m, d b / d b$ and $d b / d b+M C C 950$ groups at various time points (8, 12, 16 and 20 weeks of age). (C) KW/BW at 20 weeks of age. (D) Serum creatinine at 20 weeks of age, $F=4.329$. (E) BUN at 20 weeks of age, $F=0.361$ I. (F) Urinary ACR at various time points (8, I2, 16 and 20 weeks of age). (G) Urinary NGAL at 8 and 20 weeks of age. (H) Representative images of HE, PAS and Masson staining. Bar $=50 \mu \mathrm{m}$. (I) Glomerular sclerosis index for PAS staining. (J) Tubulointerstitial damage index for Masson staining; yellow arrows showed mesangial matrix expansion, glomerular hypertrophy, tubular dilation and interstitial inflammation in $\mathrm{db} / \mathrm{db}$ mice. (K-N) Representative immunohistochemical and immunohistochemical scores of renal sections for PCNA and $p$-NF- $\mathrm{KB}$ staining at 20 weeks of age. Bar $=50 \mu \mathrm{m}$. Data represent means \pm SEM $(n=10)$. ${ }^{\#} P<0.05$ and ${ }^{\# \#} P<0.01$ versus $\mathrm{db} / \mathrm{m}$ mice; $* P<0.05$ and $* * P<0.01$ versus $d b / d b$ mice.

Abbreviations: KW/BW, ratio of kidney weight to body weight; BUN, blood urea nitrogen; $A C R$, albumin-to-creatinine ratio; NGAL, neutrophil gelatinase-associated lipocalin; HE, hematoxylin-eosin; PAS, periodic acid-Schiff; PCNA, proliferating cell nuclear antigen; $\mathrm{p}-\mathrm{NF}-\kappa \mathrm{B}$, phosphor-nuclear factor- $\mathrm{B}$ p 65 ; SEM, standard error of mean.

of $d b / d b$ mice was increased by MCC950 treatment with IHC and WB $(P<0.05$, Figure 2D-G). MCC950 prevented diabetes-induced podocytes injury.

\section{MCC950 alleviated renal fibrosis in $\mathrm{db} / \mathrm{db}$ mice}

Expression levels of fibronectin and $\alpha$-smooth muscle actin ( $\alpha$-SMA) (both of which are markers of fibrosis) were greater in $d b / d b$ mice than in $d b / m$ mice, and were inhibited by MCC950 treatment as measured by IHC $(P<0.01$, Figure 3A-D). MCC950 treatment also suppressed the increase in fibrosis marker protein levels caused by TGF- $\beta 1$, collagen I and $\alpha$-SMA in $d b / d b$ mice, as measured by WB $(P<0.05$, Figure $3 \mathrm{E}-\mathrm{H})$. Furthermore, mRNA expression levels of TGF- $\beta 1$, fibronectin and collagen I were significantly decreased by MCC950 treatment in $d b / d b$ mice $(P<0.05$, Figure 3I-K). MCC950 effectively prevented the progression of renal fibrosis in $d b / d b$ mice.

\section{MCC950 inhibited diabetes-induced renal NLRP3 inflammasome activation in $\mathrm{db} / \mathrm{db}$ mice}

The renal expressions of NLRP3, caspase-1 and IL-1 $\beta$ were higher in $d b / d b$ mice than in $d b / m$ mice as shown by IHC and were reduced by MCC 950 treatment $(P<0.01$, Figure 4A-F). MCC950 also decreased NLRP3 protein expression in $d b / d b$ mice as measured by WB $(P<0.05$, Figure $4 \mathrm{G}-\mathrm{H})$. The activities of caspase- 1 and IL- $1 \beta$ were greater in $d b / d b$ mice and were inhibited by MCC950 

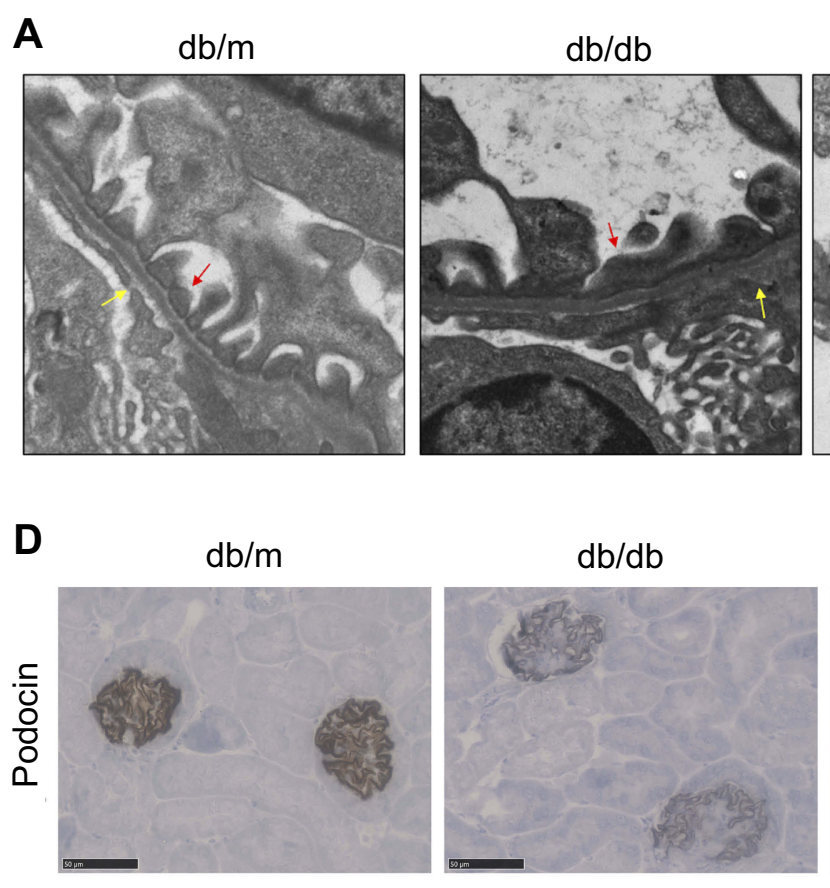

$\mathbf{F}$

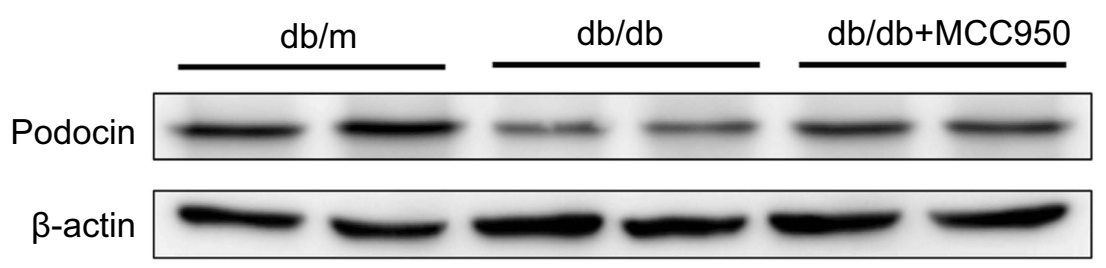

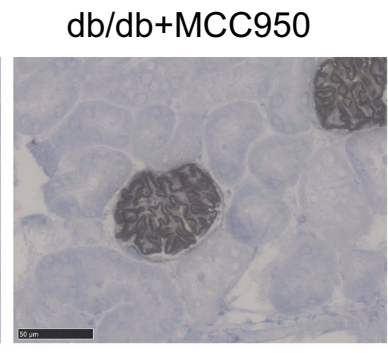

B
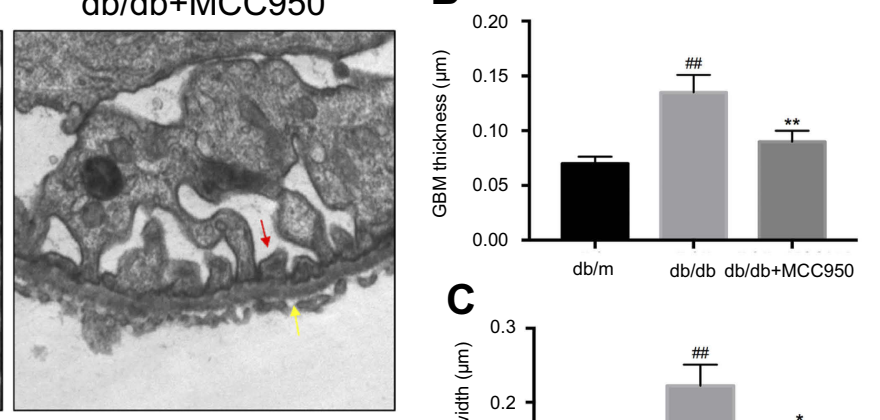

C
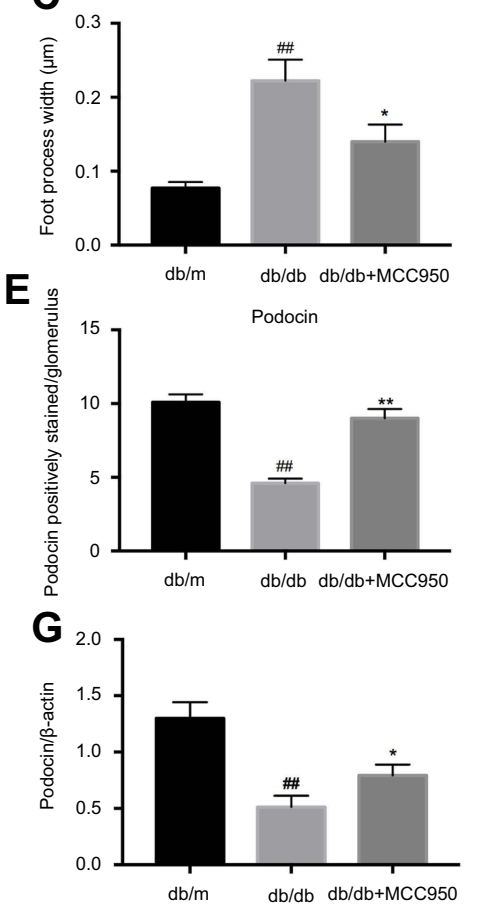

Figure 2 MCC950 attenuated podocyte injury in $\mathrm{db} / \mathrm{db}$ mice.

Notes: (A) Representative images of podocyte ultrastructure shown by transmission electron microscopy from $\mathrm{db} / \mathrm{m}$, $\mathrm{db} / \mathrm{db}$ and $\mathrm{db} / \mathrm{db}+\mathrm{MCC} 950$ groups at $20 \mathrm{weeks}$ of age (TEM $\times 15000$ ). (B) GBM thickness (yellow arrows). (C) Foot process width (red arrows). (D) Representative immunohistochemical images and (E) immunohistochemical scores of renal sections for podocin staining. Bar $=50 \mu \mathrm{m}$. (F-G) Western blot analysis of podocin in renal cortical tissue. Data represent means \pm SEM ( $\mathrm{F}=10$ ). ${ }^{\#} P<0.05$ and ${ }^{\#} P<0.01$ versus $d b / m$ mice; $* P<0.05$ and $* * P<0.01$ versus $d b / d b$ mice.

Abbreviations: TEM, transmission electron microscopy; GBM, glomerular basement membrane; SEM, standard error of mean.

treatment. The activities of caspase-1 and IL-1 $\beta$ were determined by WB according to their protein expression levels from the immature form to active form $(P<0.05$, Figure 4G, I and J). Higher expression of IL-1 $\beta$ in renal cortical tissue of $d b / d b$ mice was decreased by MCC950 treatment by ELISA $(\mathrm{F}=6.331, P<0.05$, Figure $4 \mathrm{~K})$. Therefore, MCC950 inhibited NLRP3 inflammasome activation and the activities of caspase- 1 and IL-1 $\beta$.

\section{MCC950 inhibited HG-induced NLRP3} inflammasome activation in mesangial cells Mesangial cells showed higher NLRP3 protein expression after 48-hr stimulation with $\mathrm{HG}$, as well as higher levels of mature caspase- 1 and IL- $1 \beta$ than in the NG group, that were inhibited by $0.1 \mu \mathrm{M}$ or $1 \mu \mathrm{M}$ MCC950 treatment. MCC950 inhibited NLRP3 inflammasome activation, accordingly disturbing the transformation of pro-caspase- 1 into mature caspase-1 and the production of mature IL-1 $\beta$ p17 $(P<0.05$, Figure 5A-D). Immunofluorescent images showed higher caspase- 1 expression in the $\mathrm{HG}$ group that was diminished by $0.1 \mu \mathrm{M}$ or $1 \mu \mathrm{M}$ MCC950 treatment $(P<0.05$, Figure $5 \mathrm{E})$. Higher expression of IL-1 $\beta$ in the supernatant of the $\mathrm{HG}$ group was decreased by $0.1 \mu \mathrm{M}$ or $1 \mu \mathrm{M}$ MCC950 treatment by ELISA $(\mathrm{F}=7.218, P<0.05$, Figure $5 \mathrm{~F})$.

\section{MCC950 decreased expression of fibrosis markers by inhibiting NLRP3 inflammasome activation in mesangial cells}

Protein levels of fibrosis markers TGF- $\beta 1$, collagen I and $\alpha$-SMA were higher in the HG group, as demonstrated on 
A

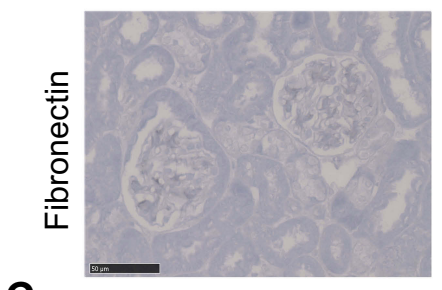

C

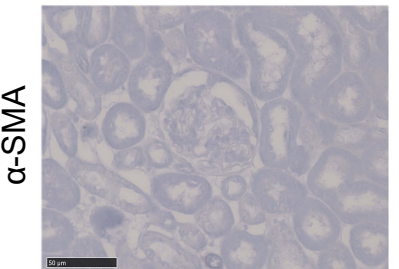

E
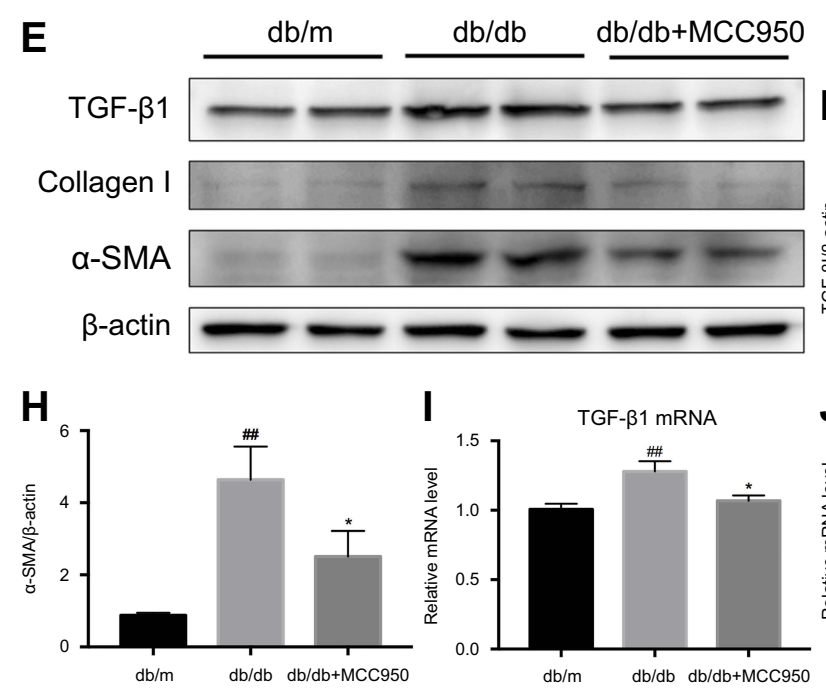

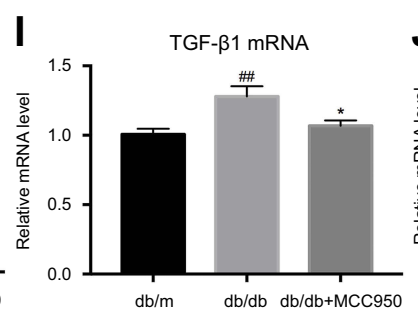

$\mathrm{db} / \mathrm{db}$
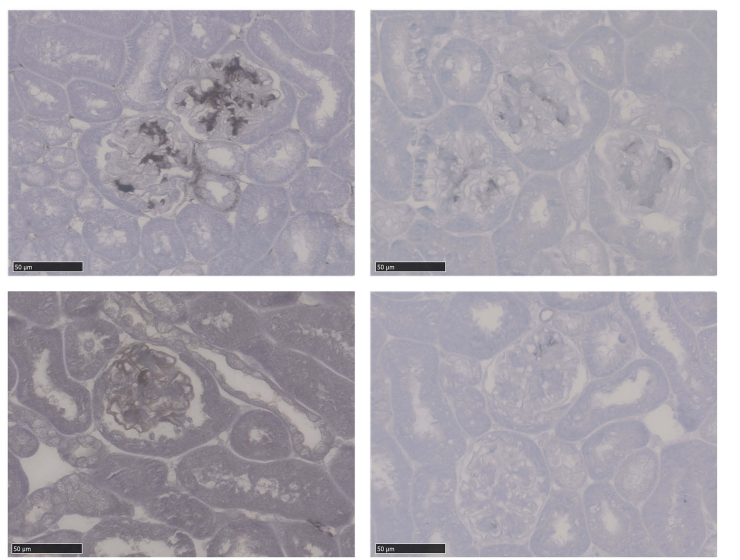

\section{$\mathbf{F}$}
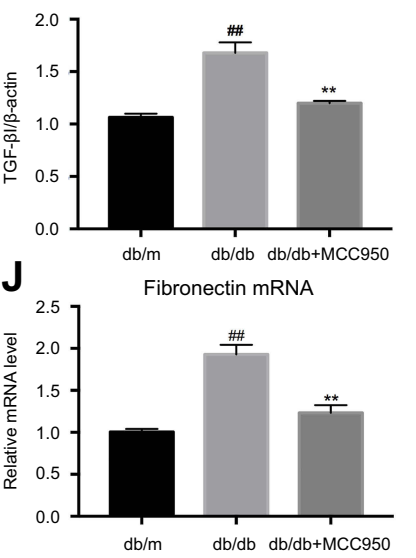

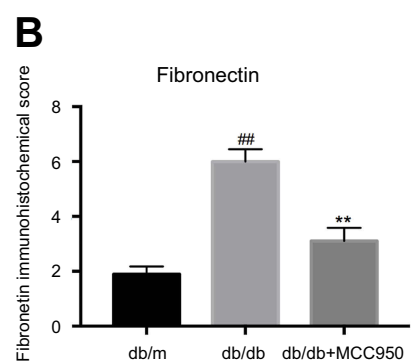

D
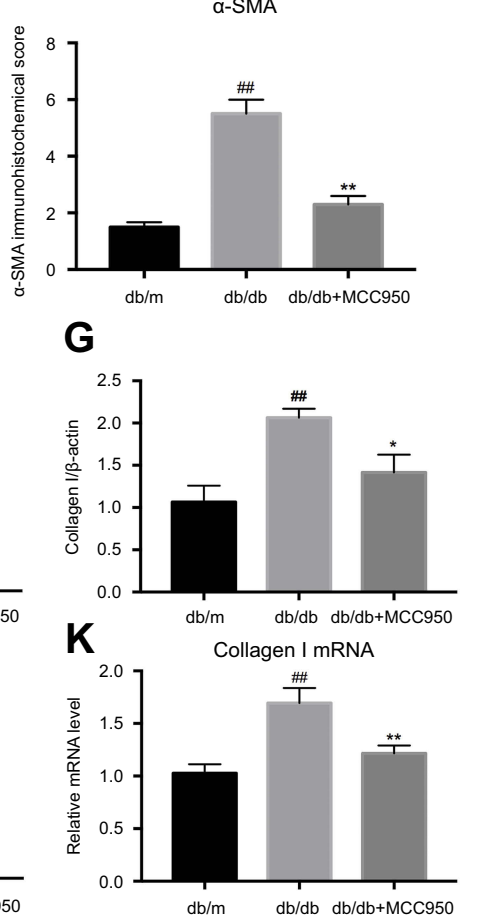

Figure 3 MCC950 alleviated renal fibrosis in $d b / d b$ mice.

Notes: $(\mathbf{A}-\mathbf{D})$ Representative immunohistochemical and immunohistochemical scores of renal sections for fibronectin and $\alpha$-SMA staining at 20 weeks of age. Bar $=50 \mu \mathrm{m}$. (E-H) Western blot analysis of TGF- $\beta$ I, fibronectin, collagen I and $\alpha$-SMA in renal cortical tissue. (I-K) Relative mRNA expression levels of TGF- $\beta$ I, fibronectin and collagen $I$ in renal cortical tissue by real-time qPCR. Data represent means \pm SEM $(n=10)$. ${ }^{\#} P<0.01$ versus $d b / m$ mice; $* P<0.05$ and $* * P<0.01$ versus $d b / d b$ mice.

Abbreviations: $\alpha$-SMA, $\alpha$-smooth muscle actin; PCR, polymerase chain reaction; SEM, standard error of mean.

WB; these levels were significantly inhibited by $0.1 \mu \mathrm{M}$ or $1 \mu \mathrm{M}$ MCC950 treatment $(P<0.05$, Figure 6A-D). The similar results were obtained by RT-qPCR. MCC950 prevented HG-induced increases mRNA expression levels of TGF- $\beta 1$, collagen $\mathrm{I}$ and fibronectin in mesangial cells $(P<0.05$, Figure 6E-G).

\section{Discussion}

Chronic low-grade sterile inflammation and proinflammatory cytokines release are thought to be crucial mechanisms in the progression of DN. ${ }^{24,25}$ In DN, the NLRP3 inflammasome is an intracellular platform that converts pro-caspase- 1 and proIL-1 $\beta$ into active forms (caspase- 1 p10/p20 and IL-1 $\beta$ p17) responding to danger signals and triggers inflammatory programmed cell death called pyroptosis. ${ }^{26,27}$ Pyroptosis features cell swelling and subsequently rupturing the cell membrane, causing massive leakage of cytosolic contents, further promoting killing by a secondary phagocyte, contributing to the expansion of the inflammatory response. ${ }^{28-30}$ MCC950 is a selective small molecule inhibitor of NLRP3 that blocks canonical and non-canonical NLRP3 activation at nanomolar concentrations. ${ }^{13}$ In recent studies, MCC950 reduced liver inflammation and fibrosis by suppression collagen I, $\alpha$-SMA and hepatic connective tissue growth factor expression in a mouse model of non-alcoholic steatohepatitis. $^{31}$ MCC950 also exerted protective effects in cholestatic liver injury and liver fibrosis by suppression hepatic expression of the pro-fibrotic markers (TGF- $\beta 1, \alpha$ SMA and Colla1) in a mouse model of bile duct ligation. ${ }^{32}$ MCC950 protected human retinal endothelial cells against 


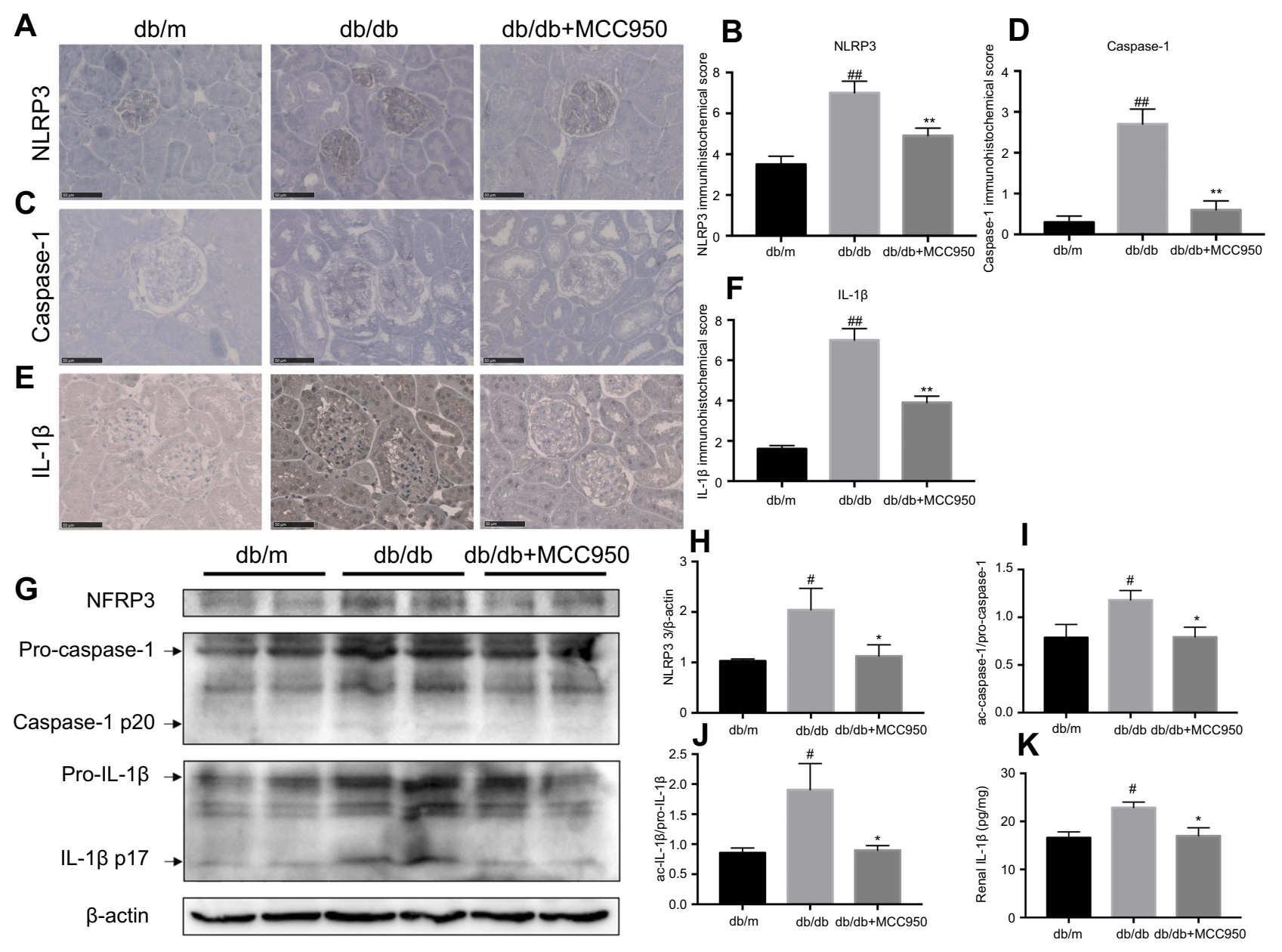

Figure 4 MCC950 inhibited diabetes-induced renal NLRP3 inflammasome activation in $\mathrm{db} / \mathrm{db}$ mice.

Notes: (A-F) Representative immunohistochemical images and immunohistochemical scores of renal sections for NLRP3, caspase-I and IL-I $\beta$ staining in renal cortical tissue from $\mathrm{db} / \mathrm{m}, \mathrm{db} / \mathrm{db}$ and $\mathrm{db} / \mathrm{db}+\mathrm{MCC} 950$ groups at 20 weeks of age. Bar $=50 \mu \mathrm{m}$. (G-J) Western blot analysis of NLRP3, caspase-I and IL-I $\beta$ in renal cortical tissue. (K) Expression of IL-I $\beta$ in renal cortical tissue at 20 weeks of age by ELISA $(F=6.33 I)$. Data represent means $\pm S E M(n=10)$. ${ }^{\#} P<0.05$ and ${ }^{\# \#} P<0.01$ versus $d b / m$ mice; ${ }^{*} P<0.05$ and $* * P<0.01$ versus $d b / d b$ mice.

Abbreviations: NLRP3, NOD-like receptor pyrin domain-containing protein 3; SEM, standard error of mean.

HG-induced dysfunction. ${ }^{33}$ MCC950 ameliorated proteinuria, pathological changes and podocyte foot process effacement in lupus-prone mice. ${ }^{34}$ Based on these studies, we proposed a model of the possible mechanism of action of MCC950 in DN (Figure 7). In our study, we used MCC950 to intervene in type 2 diabetic $d b / d b$ mice in vivo and HGinduced mesangial cells in vitro. The efficacy of MCC950 for the treatment of DN in $d b / d b$ mice has not been reported previously. MCC950 effectively inhibited expression of NLRP3 and the conversion to active forms of caspase-1 and IL-1 $\beta$ in both renal cortices of $d b / d b$ mice and in HGinduced mesangial cells. MCC950 suppressed renal inflammation by inhibiting NLRP3 inflammasome activation, the mechanism of by which MCC950 ameliorated kidney injury in DN.
Albuminuria is the most impotent clinical feature of DN, primarily caused by an impaired glomerular filtration barrier. Urinary ACR is the most important marker for evaluating early renal decline and diagnostic basis in diabetic nephropathy. ${ }^{3}$ Podocytes are the weakest link in the glomerular filtration barrier. ${ }^{35}$ Podocyte damage gives rise to albuminuria in $\mathrm{DN}^{36}$ and NLRP3 inflammasome activation in podocytes contributes to podocyte loss. ${ }^{12,34}$ Podocytes are highly differentiated epithelial cells. Podocyte damage leads to irreversible renal decline. ${ }^{37}$ In this study, MCC950 treatment ameliorated podocyte foot process effacement and thickened GBM in $d b / d b$ mice. Podocin is a glomerular slit diaphgram protein between neighboring podocytes, and a critical component of glomerular filtration barrier, ${ }^{38}$ that plays 


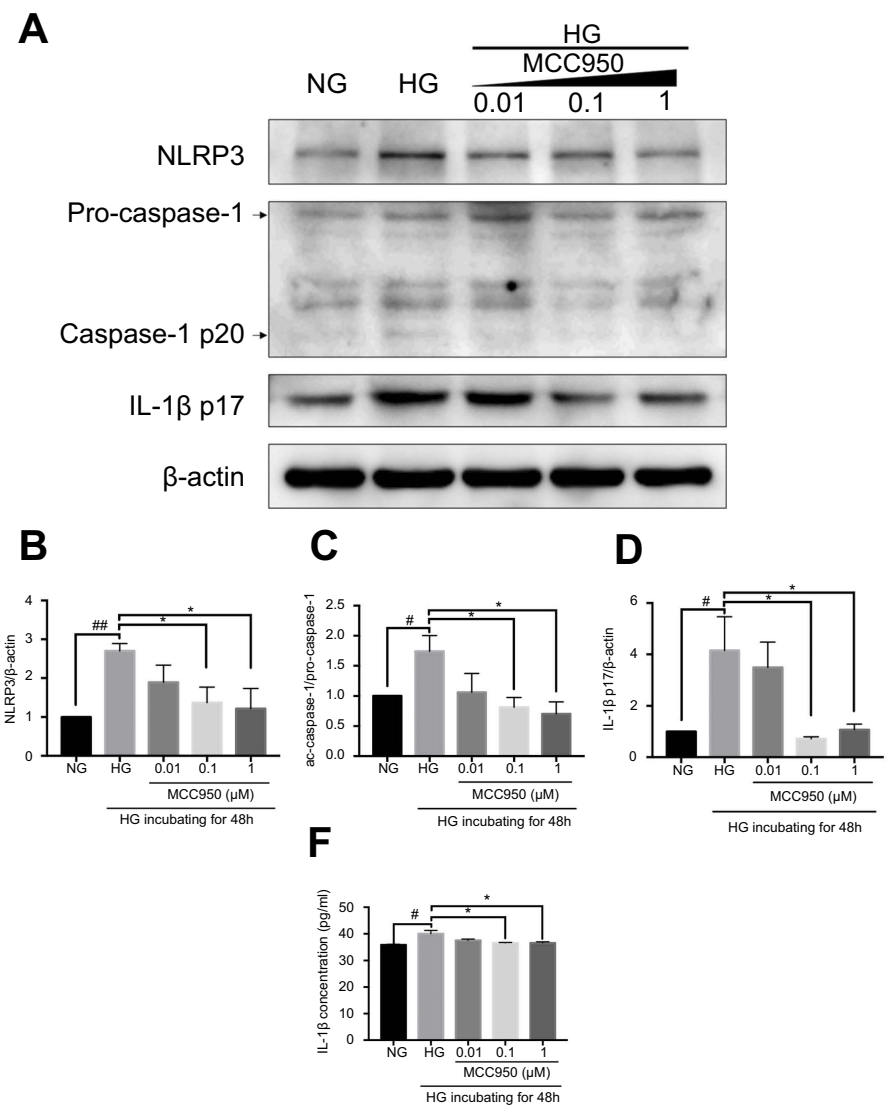

E

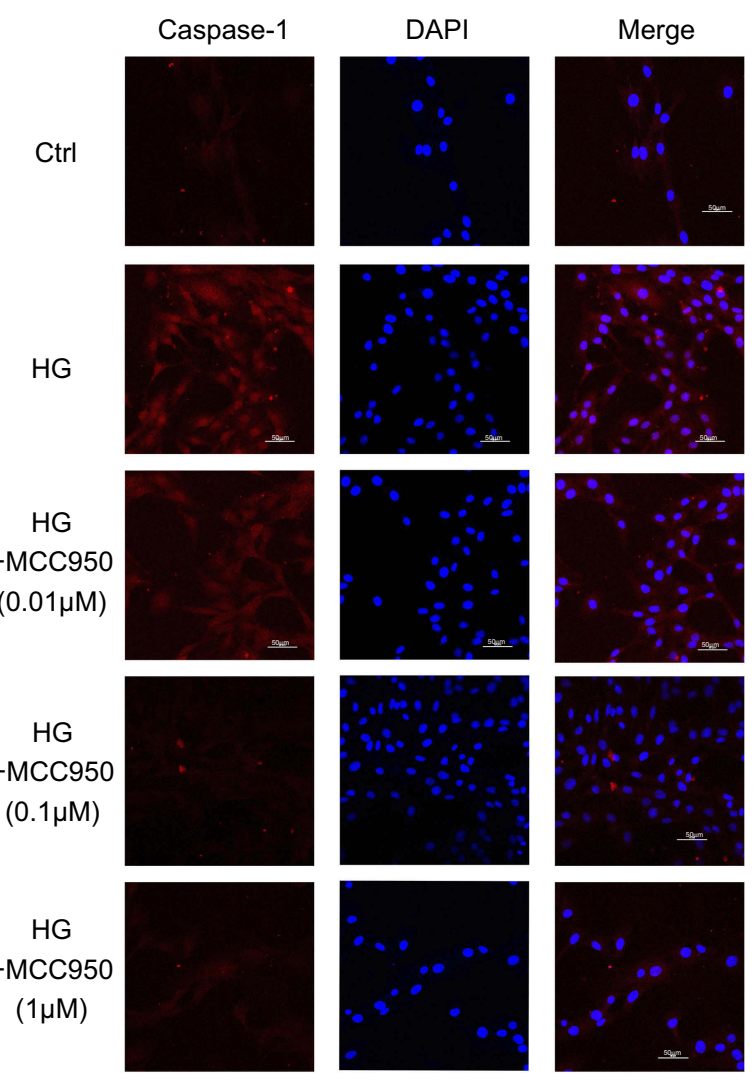

Figure 5 MCC950 inhibited HG-induced NLRP3 inflammasome activation in mesangial cells.

Notes: (A-D) Western blot analysis of NLRP3 ( $F=3.499)$, caspase-I $(F=3.508)$ and IL-I $\beta(F=4.67 I)$ in mesangial cells. (E) Immunofluorescent localization of caspase-I (red) in mesangial cells with nuclei staining by DAPI (blue). Bar $=50 \mu \mathrm{M}$. (F) Expression of IL-I $\beta$ in cell culture supernatants by ELISA (F=7.2I8). Data represent means \pm SEM. ${ }^{\#} P<0.05$ and ${ }^{\#} P<0.01$ versus $N G ; * P<0.05$ and $* * P<0.01$ versus $H G$.

Abbreviations: NLRP3, NOD-like receptor pyrin domain-containing protein 3; NG, normal-glucose group; HG, high-glucose group; SEM, standard error of mean.

a key role in maintaining the normal structure and function of podocytes. ${ }^{37}$ Decreased expression of podocin suggests that podocyte foot processes fuse, ${ }^{39}$ destroying the glomerular filtration barrier, resulting in production of albuminuria. ${ }^{40}$ In our study, the expression of podocin was markedly elevated by MCC950 treatment in $d b / d b$ mice. Therefore, MCC950 protected against podocyte injury to reduce urinary ACR and improved renal function in $d b / d b$ mice.

The typical pathological features of early DN are glomerular hypertrophy, thickened glomerular basement membrane and mesangial expansion with increased matrix deposition. ${ }^{1}$ Renal fibrosis of both glomerular and tubulointerstitial compartments, characterized by extracellular matrix (ECM) accumulation, is recognized as a basic mechanism leading to diabetic glomerular disease. ${ }^{41,42}$ Mesangial cells as intrinsic renal cells secrete a large number of proinflammatory and profibrotic cytokines responding to injury in $\mathrm{DN}{ }^{41}$ IL- $1 \beta$ has been demonstrated to stimulate production of TGF- $\beta 1$, fibronectin, collagen I and mesangial proliferation. ${ }^{24,25,43}$ The positive PCNA and p-NF- $\mathrm{\kappa B}$ immunohistochemistry staining also confirmed the proliferation and activation of mesangial cells in $d b / d b$ mice. Therefore, we chose mesangial cells in vitro to study the mechanism of MCC950 in DN. TGF- $\beta 1$ is a major cytokine secreted by mesangial cells that mediates the development of DN. It has many biological activities such as regulating cell proliferation, differentiation and migration. TGF- $\beta 1$ is also a key cytokine mediating collagen deposition in kidney, including promoting the production of ECM, inhibiting the degradation of ECM and participating in renal fibrosis. ${ }^{44}$ ECM in patients with $\mathrm{DN}$ is produced by mesangial cells and is primarily composed of fibronectin, collagen IV and a few collagen I. The expression of collagen I is low level in normal kidney tissue; however, it is significantly increased under high glucose stimulation. The expression of $\alpha$-SMA in normal mesangial cells is very weak. However, the 
A
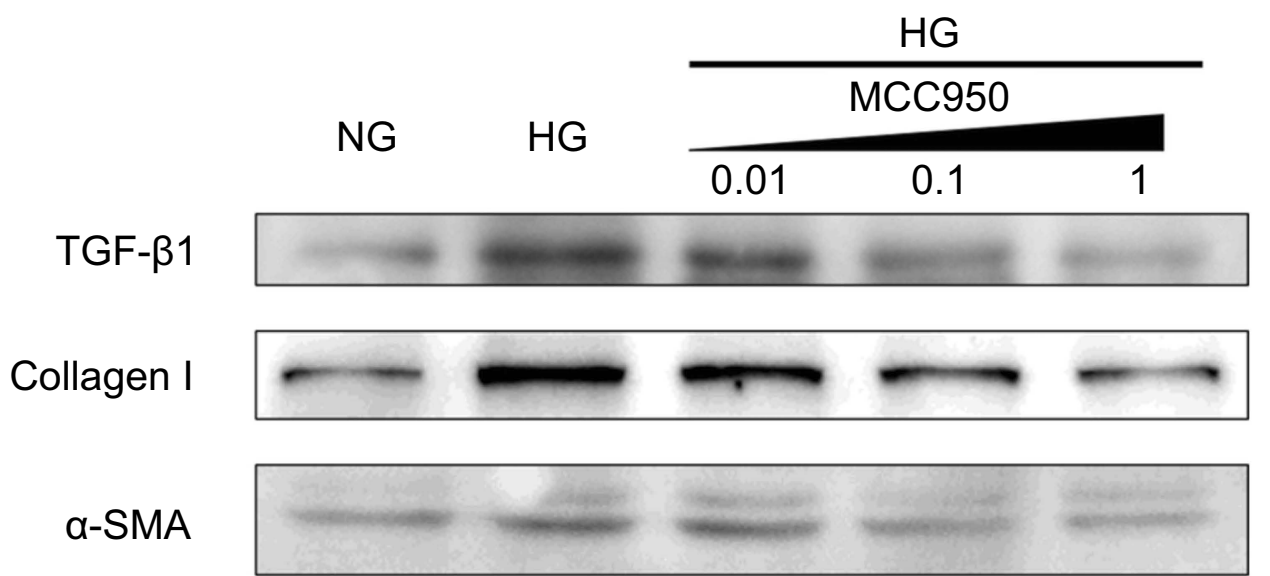

$\beta$-actin

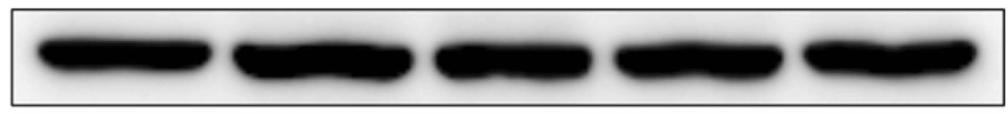

B

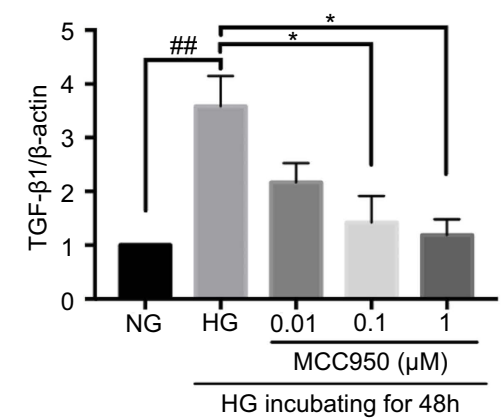

E

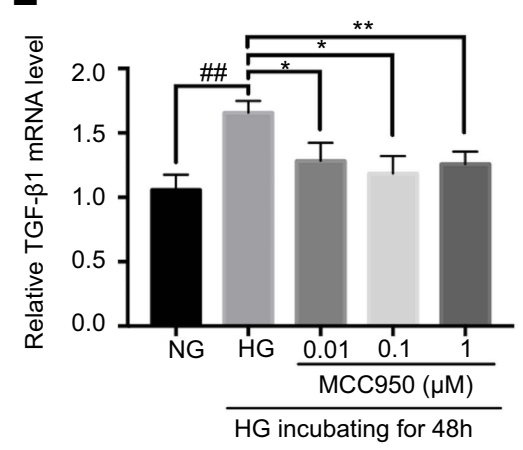

C

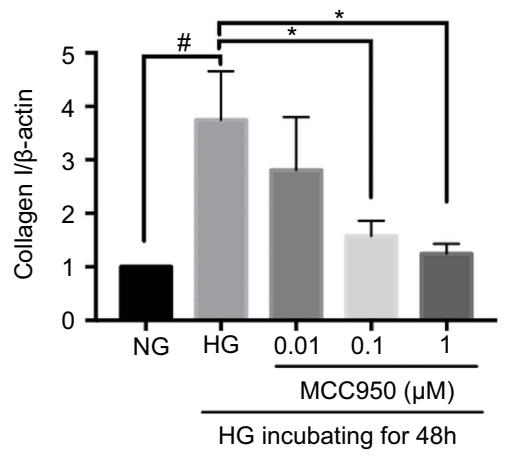

$\mathbf{F}$

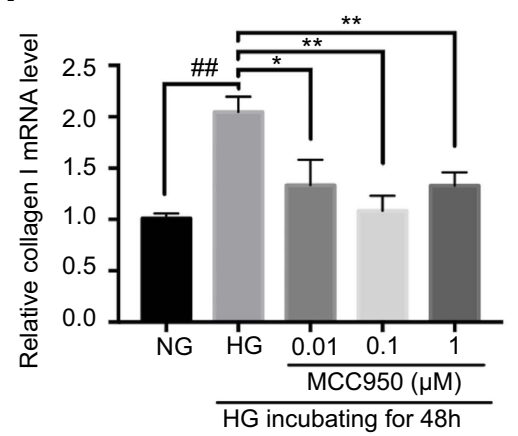

D

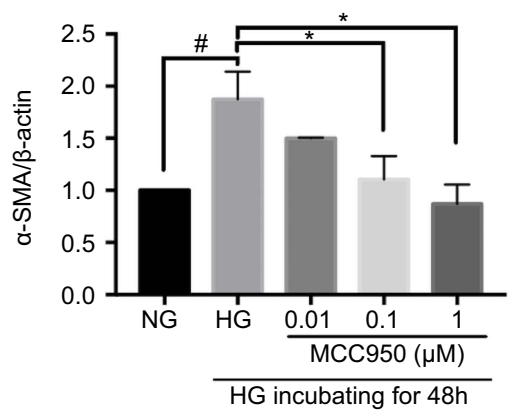

G

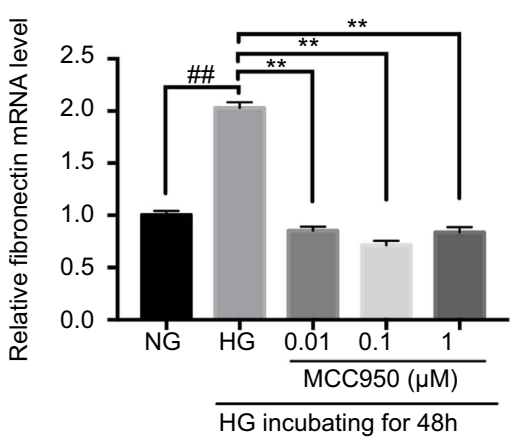

Figure 6 MCC950 decreased expression of fibrosis markers by inhibiting NLRP3 inflammasome activation in mesangial cells.

Notes: (A-D) Western blot analysis of TGF- $\beta$ I ( $F=7.218)$, collagen I $(F=3.5 I 4)$ and $\alpha-S M A(F=5.409)$ in mesangial cells: NG, HG, HG+MCC950 with the indicated concentration. (E-G) Relative mRNA expression levels of TGF- $\beta$ I $(F=3.674)$, collagen I $(F=7.955)$ and fibronectin $(F=49.7)$ in mesangial cells. Data represent means \pm SEM. ${ }^{\#} P<0.05$ and ${ }^{\# \#} P<0.01$ versus $N G ; * P<0.05$ and $* * P<0.01$ versus $H G$.

Abbreviations: $\alpha$-SMA, $\alpha$-smooth muscle actin; NG, normal-glucose group; HG, high-glucose group; SEM, standard error of mean.

expression of $\alpha$-SMA in mesangial cells is increased under high glucose stimulation, suggesting that mesangial cells undergo phenotypic transformation from resting state to secretion/proliferative state. ${ }^{45}$ In our study, MCC950 significantly decreased mesangial cells proliferation and the expression levels of fibrosis markers (TGF- $\beta 1$, fibronectin, collagen I and $\alpha$-SMA) both in renal cortices of $d b / d b$ mice and in HG-induced mesangial cells.

Urinary NGAL as a marker of renal tubular injury is also an important marker for evaluating early progressive renal decline in type 2 diabetes mellitus. ${ }^{3}$ Inflammatory cell infiltration in the tubules and interstitium is also one of 


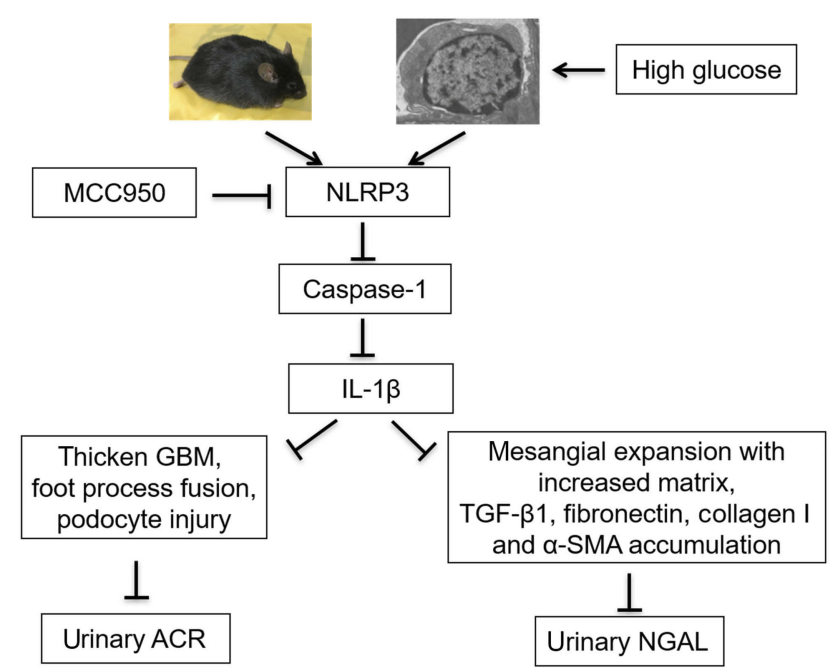

Figure 7 A diagram of a model of the possible mechanism of action of MCC950. Abbreviations: NLRP3, NOD-like receptor pyrin domain-containing protein 3; GBM, glomerular basement membrane; $\alpha$-SMA, $\alpha$-smooth muscle actin; ACR, albumin-to-creatinine ratio; NGAL, neutrophil gelatinase-associated lipocalin.

the pathological changes of $\mathrm{DN}$, leading to renal fibrosis. In glomerular diseases, the development of glomerular inflammation precedes interstitial fibrosis. ${ }^{41}$ Furthermore, NLRP3 inflammasome activation also occurs in intrinsic renal cells such as tubular epithelial cells. ${ }^{11,12}$ Knockdown of NLRP3 alleviated high glucose-induced epithelial-tomesenchymal transition in human renal tubular cells. ${ }^{46}$ MCC950 inhibited NLRP3 inflammasome activation in tubular epithelial cells of $d b / d b$ mice. These also can explain how MCC950 significantly decreased urinary NGAL as a marker of renal tubular injury and fibrosis markers in $d b / d b$ mice. MCC950 also ameliorated pathologic changes, including glomerular sclerosis and tubular damage in $d b / d b$ mice. These data suggested that MCC950 prevents renal fibrosis from renal decline by inhibiting NLRP3 inflammasome activation in DN. Nevertheless, one limitation of this study is that we only used mesangial cells in vitro to study the mechanism of MCC950. In the future, we will further investigate the role of MCC950 in podocytes. However, there are always some differences between mice model and human, and so, this efficacy of MCC950 in DN requires further clinical investigation.

We found that MCC950 treatment improved renal function and pathologic changes in $d b / d b$ mice without affecting BW and blood glucose levels. H.L. Kammoun et al confirmed the same results that MCC950 did not impact BW and blood glucose levels in $d b / d b$ mice. ${ }^{47}$ Inhibition of the NLRP3 inflammasome by MCC950 ameliorated kidney injury in $\mathrm{DN}$; the renoprotection of MCC950 for DN occurred independently of BW and blood glucose levels.

\section{Conclusion}

The data presented in this study suggested that MCC950 effectively ameliorates kidney injury in DN, independent of BW and blood glucose levels. MCC950 inhibited NLRP3 inflammasome activation to reduce the production of active caspase- 1 and IL-1 $\beta$. These phenomena might result in reducing urinary ACR and urinary NGAL, improving renal function and alleviating podocyte injury and renal fibrosis. Therefore, MCC950 may be a promising therapeutic strategy to prevent the progression of DN.

\section{Acknowledgments}

This work was supported by grants from the Chinese National Key Technology R and D Program, Ministry of Science and Technology (No. 2017YFC0907601, No. 2017YFC0907602, and 2017YFC0807603) and the Natural Science Foundation of China (No. 81770724).

\section{Disclosure}

The authors report no conflicts of interest in this work.

\section{References}

1. Umanath K, Lewis JB. Update on diabetic nephropathy: core curriculum 2018. Am J Kidney Dis. 2018;71(6):884-895. doi:10.1053/j. ajkd.2017.10.026

2. Wada J, Makino H. Innate immunity in diabetes and diabetic nephropathy. Nat Rev Nephrol. 2015;12(1):13-26. doi:10.1038/nrneph.2015.175

3. Nowak N, Skupien J, Smiles AM, et al. Markers of early progressive renal decline in type 2 diabetes suggest different implications for etiological studies and prognostic tests development. Kidney Int. 2018;93(5):1198-1206. doi:10.1016/j.kint.2017.11.024

4. Flyvbjerg A. The role of the complement system in diabetic nephropathy. Nat Rev Nephrol. 2017;13(5):311-318. doi:10.1038/ nrneph.2017.31

5. Qiu YY, Tang LQ. Roles of the NLRP3 inflammasome in the pathogenesis of diabetic nephropathy. Pharmacol Res. 2016;114:251-264. doi:10.1016/j.phrs.2016.11.004

6. Lee HM, Kim JJ, Kim HJ, Shong M, Ku BJ, Jo EK. Upregulated NLRP3 inflammasome activation in patients with type 2 diabetes. Diabetes. 2013;62(1):194-204. doi:10.2337/db12-0420

7. El-Horany HE, Abd-Ellatif RN, Watany M, Hafez YM, Okda HI. NLRP3 expression and urinary HSP72 in relation to biomarkers of inflammation and oxidative stress in diabetic nephropathy patients. IUBMB Life. 2017;69(8):623-630. doi:10.1002/iub.1645

8. Leemans JC, Kors L, Anders HJ, Florquin S. Pattern recognition receptors and the inflammasome in kidney disease. Nat Rev Nephrol. 2014;10(7):398-414. doi:10.1038/nrneph.2014.91

9. Lamkanfi M, Dixit Vishva M. Mechanisms and functions of inflammasomes. Cell. 2014;157(5):1013-1022. doi:10.1016/j. cell.2014.04.007

10. Lorenz G, Darisipudi MN, Anders H-J. Canonical and non-canonical effects of the NLRP3 inflammasome in kidney inflammation and fibrosis. Nephrol Dialysis Trans. 2014;29(1):41-48. doi:10.1093/ ndt/gft332

11. Sakai N, Wada T. Revisiting inflammation in diabetic nephropathy: the role of the NLRP3 inflammasome in glomerular resident cells. Kidney Int. 2015;87(1):12-14. doi:10.1038/ki.2014.322 
12. Shahzad K, Bock F, Dong W, et al. NLRP3-inflammasome activation in non-myeloid-derived cells aggravates diabetic nephropathy. Kidney Int. 2015;87(1):74-84. doi:10.1038/ki.2014.271

13. Coll RC, Robertson AA, Chae JJ, et al. A small-molecule inhibitor of the NLRP3 inflammasome for the treatment of inflammatory diseases. Nat Med. 2015;21(3):248-255. doi:10.1038/nm.3806

14. Salla M, Butler MS, Pelingon R, et al. Identification, synthesis, and biological evaluation of the major human metabolite of NLRP3 inflammasome inhibitor MCC950. ACS Med Chem Lett. 2016;7 (12):1034-1038. doi:10.1021/acsmedchemlett.6b00198

15. Ludwig-Portugall I, Bartok E, Dhana E, et al. An NLRP3-specific inflammasome inhibitor attenuates crystal-induced kidney fibrosis in mice. Kidney Int. 2016;90(3):525-539. doi:10.1016/j.kint.2016.03.035

16. Krishnan SM, Ling YH, Huuskes BM, et al. Pharmacological inhibition of the NLRP3 inflammasome reduces blood pressure, renal damage and dysfunction in salt-sensitive hypertension. Cardiovasc Res. 2018;115(4):776-87.

17. van der Heijden T, Kritikou E, Venema W, et al. NLRP3 inflammasome inhibition by MCC950 reduces atherosclerotic lesion development in apolipoprotein E-deficient mice-brief report. Arterioscler Thromb Vasc Biol. 2017;37(8):1457-1461. doi:10.1161/ ATVBAHA.117.309575

18. Kim RY, Pinkerton JW, Essilfie AT, et al. Role for NLRP3 inflammasome-mediated, IL-1beta-dependent responses in severe, steroid-resistant Asthma. Am J Respir Crit Care Med. 2017;196 (3):283-297. doi:10.1164/rccm.201609-18300C

19. Hummel KP, Dickie MM, Coleman DL. Diabetes, a new mutation in the mouse. Science. 1966;153(3740):1127-1128.

20. Sharma K, McCue P, Dunn SR. Diabetic kidney disease in the $\mathrm{db} / \mathrm{db}$ mouse. Am J Physiol Renal Physiol. 2003;284(6):F11381144. doi:10.1152/ajprenal.00140.2002

21. Zhu X, Zhang C, Fan Q, et al. Inhibiting microRNA-503 and microRNA-181d with losartan ameliorates diabetic nephropathy in KKAy mice. Med Sci Monit. 2016;22:3902-3909.

22. Yiu WH, Wong DW, Wu $\mathrm{HJ}$, et al. Kallistatin protects against diabetic nephropathy in $\mathrm{db} / \mathrm{db}$ mice by suppressing AGE-RAGEinduced oxidative stress. Kidney Int. 2016;89(2):386-398. doi:10.1038/ki.2015.331

23. Canaud G, Bienaime F, Viau A, et al. AKT2 is essential to maintain podocyte viability and function during chronic kidney disease. Nat Med. 2013;19(10):1288-1296. doi:10.1038/nm.3313

24. Navarro-Gonzalez JF, Mora-Fernandez C. The role of inflammatory cytokines in diabetic nephropathy. J Am Soc Nephrol. 2008;19 (3):433-442. doi:10.1681/ASN.2007091048

25. Hickey FB, Martin F. Diabetic kidney disease and immune modulation. Curr Opin Pharmacol. 2013;13(4):602-612. doi:10.1016/j.coph.2013.05.002

26. Yuan J, Najafov A, Py BF. Roles of caspases in necrotic cell death. Cell. 2016;167(7):1693-1704. doi:10.1016/j.cell.2016.11.047

27. Risdon RA, Sloper JC, De Wardener HE. Relationship between renal function and histological changes found in renal-biopsy specimens from patients with persistent glomerular nephritis. Lancet. 1968;2 (7564):363-366.

28. Shi J, Zhao Y, Wang K, et al. Cleavage of GSDMD by inflammatory caspases determines pyroptotic cell death. Nature. 2015;526 (7575):660-665. doi:10.1038/nature15514

29. Jorgensen I, Miao EA. Pyroptotic cell death defends against intracellular pathogens. Immunol Rev. 2015;265(1):130-142. doi:10.1111/imr.12287

30. Yuan -Y-Y, Xie K-X, Wang S-L, Yuan L-W. Inflammatory caspase-related pyroptosis: mechanism, regulation and therapeutic potential for inflammatory bowel disease. Gastroenterol Rep. 2018;6(3):167-176. doi:10.1093/gastro/goy011
31. Mridha AR, Wree A, Robertson AAB, et al. NLRP3 inflammasome blockade reduces liver inflammation and fibrosis in experimental NASH in mice. J Hepatol. 2017;66(5):1037-1046. doi:10.1016/j. jhep.2017.01.022

32. Qu J, Yuan Z, Wang G, Wang X, Li K. The selective NLRP3 inflammasome inhibitor MCC950 alleviates cholestatic liver injury and fibrosis in mice. Int Immunopharmacol. 2019;70:147-155. doi:10.1016/j.intimp.2019.02.016

33. Zhang Y, Lv X, Hu Z, et al. Protection of MCC950 against high-glucose-induced human retinal endothelial cell dysfunction. Cell Death Dis. 2017;8(7):e2941. doi:10.1038/cddis.2017.518

34. Fu R, Guo C, Wang S, et al. Podocyte activation of NLRP3 inflammasomes contributes to the development of proteinuria in lupus nephritis. Arthritis Rheum. 2017;69(8):1636-1646. doi:10.1002/art.40155

35. Pagtalunan ME, Miller PL, Jumping-Eagle S, et al. Podocyte loss and progressive glomerular injury in type II diabetes. $J$ Clin Invest. 1997;99(2):342-348. doi:10.1172/JCI119163

36. Xu L, Fan Q, Wang X, et al. Ursolic acid improves podocyte injury caused by high glucose. Nephrol Dialysis Trans. 2017;32 (8):1285-1293. doi:10.1093/ndt/gfv382

37. Greka A, Mundel P. Cell biology and pathology of podocytes. Annu Rev Physiol. 2012;74:299-323. doi:10.1146/annurev-physiol-020911-153238

38. Mollet G, Ratelade J, Boyer O, et al. Podocin inactivation in mature kidneys causes focal segmental glomerulosclerosis and nephrotic syndrome. J Am Soc Nephrol. 2009;20(10):2181-2189. doi:10.1681/ ASN.2009040379

39. Mundel P, Shankland SJ. Podocyte biology and response to injury. J Am Soc Nephrol. 2002;13(12):3005-3015.

40. Huber TB, Benzing T. The slit diaphragm: a signaling platform to regulate podocyte function. Curr Opin Nephrol Hypertens. 2005;14(3):211-216.

41. Meng XM, Nikolic-Paterson DJ, Lan HY. Inflammatory processes in renal fibrosis. Nat Rev Nephrol. 2014;10(9):493-503. doi:10.1038/ nrneph.2014.114

42. Wang E-M, Fan Q-L, Yue Y, Xu L. Ursolic acid attenuates high glucose-mediated mesangial cell injury by inhibiting the phosphatidylinositol 3-Kinase/Akt/Mammalian target of rapamycin (PI3K/Akt/ mTOR) signaling pathway. Med Sci Monit. 2018;24:846-854.

43. Vesey DA, Cheung C, Cuttle L, Endre Z, Gobe G, Johnson DW. Interleukin-1 $\beta$ stimulates human renal fibroblast proliferation and matrix protein production by means of a transforming growth factor- $\beta$-dependent mechanism. J Lab Clin Med. 2002;140(5):342-350. doi:10.1067/mlc.2002.128468

44. Ma X, Ding J, Min H, Wen Y, Gao Q. Protective role of low-dose TGF- $\beta 1$ in early diabetic nephropathy induced by streptozotocin. Int Immunopharmacol. 2013;17(3):752-758. doi:10.1016/j. intimp.2013.08.023

45. Cheng H, Chen C, Wang S, Ding G, Shi M. The effects of urokinase-type plasminogen activator (uPA) on cell proliferation and phenotypic transformation of rat mesangial cells induced by high glucose. Diabetes Res Clin Pract. 2014;103(3):489-495. doi:10.1016/j.diabres.2013.11.016

46. Song S, Qiu D, Luo F, et al. Knockdown of NLRP3 alleviates high glucose or TGFB1-induced EMT in human renal tubular cells. J Mol Endocrinol. 2018;61(3):101-113. doi:10.1530/JME-18-0069

47. Kammoun HL, Allen TL, Henstridge DC, et al. Evidence against a role for NLRP3-driven islet inflammation in $\mathrm{db} / \mathrm{db}$ mice. Mol Metab. 2018;10:66-73. doi:10.1016/j.molmet.2018.02.001 


\section{Publish your work in this journal}

Diabetes, Metabolic Syndrome and Obesity: Targets and Therapy is an international, peer-reviewed open-access journal committed to the rapid publication of the latest laboratory and clinical findings in the fields of diabetes, metabolic syndrome and obesity research. Original research, review, case reports, hypothesis formation, expert opinion and commentaries are all considered for publication. The manuscript management system is completely online and includes a very quick and fair peer-review system, which is all easy to use. Visit http://www.dovepress.com/testimonials.php to read real quotes from published authors.

Submit your manuscript here: https://www.dovepress.com/diabetes-metabolic-syndrome-and-obesity-targets-and-therapy-journal 